\title{
La competitividad turística: imperativo para Manzanillo, Colima
}

\author{
DOI: 10.22403/UQROOMX/TYP05/02 \\ $M^{\circ}$ \\ Carlos Mario Amaya Molinar \\ Ernesto Manuel Conde Pérez \\ Rafael Covarrubias Ramírez* \\ Resumen \\ La ventaja competitiva en el turismo se refiere a la habilidad de un \\ destino para emplear de manera efectiva sus recursos en el largo \\ plazo. Se han publicado varios modelos para analizar los factores \\ que determinan que un destino turístico sea más competitivo \\ con respecto a otro. Entre los modelos estudiados se encuentran \\ el modelo de competitividad del Diamante de Porter, el modelo de \\ Crouch y Ritchie, y el de Dwyer y Kim. \\ Manzanillo es la zona turística más importante de Colima.Sin \\ embargo, existen indicadores, tales como la ocupación anual y la \\ atracción de inversión, que sugieren que este polo de desarrollo \\ no puede ser considerado competitivo en el plano nacional ni en \\ el regional. Otros elementos -y que aquí se analizan- son el nivel \\ de satisfacción y la valoración de los turistas, de los habitantes \\ y de los empresarios en torno a los atributos de este destino, \\ así como las sugerencias de estos tres grupos para mejorar la \\ competitividad.
}

Palabras $\mid$ Atributos, competitividad, modelos, turismo, ventajas.

CLAVE

*Universidad de Colima, Escuela de Turismo/cmamaya@ucol.mx / conde@ucol.mx / covra@ucol.mx 


\section{Introducción}

En la economía mundial acontecen actualmente profundas transformaciones, por lo que se necesitan herramientas que garanticen mayores condiciones de competitividad, entendiendo como tal la capacidad de una empresa, industria o país para superar a los competidores.

Al inicio del siglo XXI, el concepto de competitividad se encuentra en el centro de las discusiones sobre estrategias de desarrollo de países, empresas e instituciones. Los avances en materia de competitividad aparecen como objetivos de todo tipo de organizaciones; sin embargo, el término puede tener significados muy distintos, dependiendo del contexto en el que se mencione.

El presente trabajo se estructura en tres apartados: la ventaja comparativa y competitiva en el turismo, el análisis de los modelos de competitividad turística poniendo de manifiesto la complejidad del concepto de competitividad y su naturaleza multidimensional, y la situación de la competitividad turística en Manzanillo.

\section{Ventajas competitivas y comparativas como base de los modelos de competitividad turística}

La investigación empírica de Michael E. Porter a finales de los años ochenta sobre la ventaja competitiva de diferentes naciones evidenció que las empresas líderes en cualquier campo tienden a agruparse en áreas geográficas relativamente pequeñas. Esas agrupaciones se han denominado conglomerados o clusters competitivos. De esta forma, dentro de un país o una región se van creando grupos completos de industrias relacionadas o clusters altamente eficientes, que permiten crear una ventaja competitiva sostenible.

En el análisis de la competitividad en los destinos turísticos, Crouch y Ritchie (1999) introducen la teoría de la ventaja comparativa y de la ventaja competitiva. Según estos autores, la ventaja comparativa hace referencia a los factores de los que está dotado el destino turístico, incluyendo tanto a los que ocurren de forma natural como a aquellos que han sido creados. En este sentido, Porter (1998) agrupa estos factores en cinco grandes categorías: recursos humanos, recursos físicos, recursos de conocimientos (científicos), recursos de capital e infraestructura. Sin embargo, Crouch y Ritchie (1999) apuntan 
que, además de estos cinco grupos (que son válidos para cualquier subsector del sector servicios), habría que tomar en cuenta también los recursos históricos y culturales. Además hay que considerar que los recursos de un destino turístico pueden cambiar a lo largo del tiempo, lo que puede alterar su ventaja comparativa.

Las ventajas comparativas de un destino turístico están representadas por el paisaje, la flora, la fauna, el clima y el patrimonio histórico-cultural. Los recursos turísticos, a diferencia de los de una industria, no suelen experimentar agotamiento como resultado de su uso, de allí que la competitividad debe tener un tratamiento diferente.

La ventaja competitiva en el turismo concierne a la habilidad de un destino para emplear de forma efectiva sus recursos en el largo plazo.

\section{Modelos de competitividad turística: similitudes y diferencias}

Se han desarrollado varios modelos para analizar los factores que determinan que un destino turístico sea más competitivo con respecto a otro, entre ellos podemos citar el modelo de competitividad del Diamante de Porter, y los modelos de competitividad de destinos turísticos de Crouch y Ritchie y de Dwyer y Kim, respectivamente.

El modelo de competitividad del Diamante de Porter es una metodología para diagnosticar y establecer estrategias desde la visión de la empresa, para ser competitivos en un mundo globalizado.Al respecto, Porter (1998) ha señalado que en la actual economía global la competitividad ya no está limitada a aquellos países con legados favorables, sino que cada país elige su propia prosperidad al organizar sus políticas, leyes e instituciones con base en la productividad. Según lo planteado por el autor, la fuente de la competitividad económica está sustentada en los determinantes de la ventaja competitiva: cuatro grandes atributos principales y dos secundarios (figura I). Los atributos principales son: I) condiciones de los factores de producción, 2) condiciones de la demanda, 3 ) industrias relacionadas y de apoyo, y 4) estrategias de la empresa, estructura del sector y rivalidad local entre las empresas. Los factores secundarios son los hechos fortuitos y el gobierno.

A Crouch y Ritchie corresponde el mérito de haber sido los pioneros en el desarrollo del primer modelo para evaluar la competitividad de los destinos 


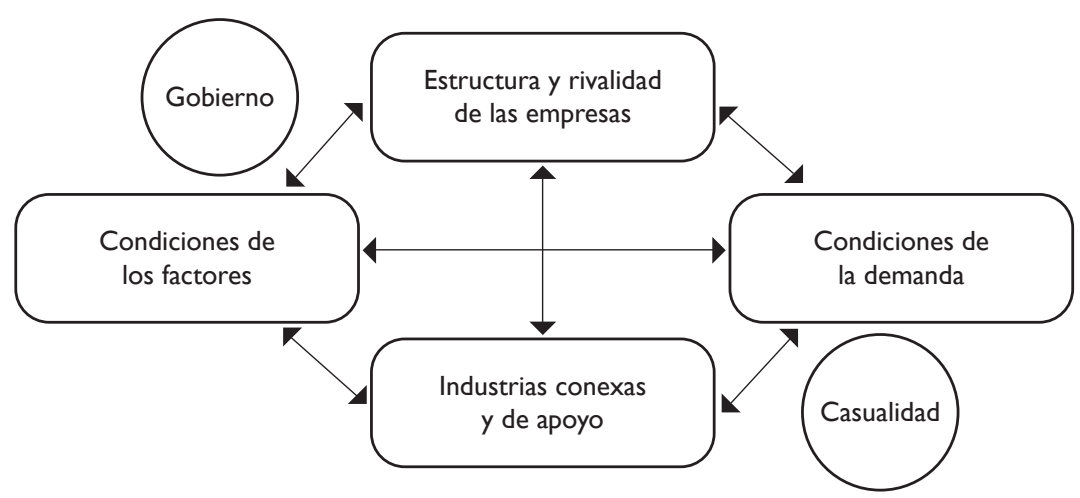

Figura I. Determinantes de la competitividad (conocido como El Diamante de Poder)

turísticos de larga distancia. Para estos investigadores, la competitividad de los destinos turísticos está asociada a la prosperidad de los residentes, por ser los principales beneficiarios; competitividad y sostenibilidad están estrechamente relacionadas, son interdependientes.

El modelo conceptual de Crouch y Ritchie (1999) no es predictivo ni causal, sino explicativo; se asienta fundamentalmente sobre dos factores que pudiéramos considerar constituyen su base: los recursos y atractivos medulares y los recursos y factores de apoyo (figura 2). Estos factores se complementan con la gerencia del destino, los calificadores o determinantes condicionantes y amplificadores, el entorno competitivo local y global,y la política de planificación y desarrollo del turismo.

Frente a este modelo, Dwyer y Kim (2003) proponen un modelo integrado, que básicamente sigue al anterior, pero introducen aspectos como los recursos heredados $y$, además, los recursos creados tienen su propia identidad, la igual que los factores y recursos complementarios. La gestión del destino y las condiciones de la demanda forman, en opinión de Dwyer y Kim, las condiciones locales, que pueden ejercer una influencia positiva o negativa sobre la competitividad. 
Modelo de competitividad de Ritchie y Crouch (2000)

Competitividad y sostenibilidad del destino

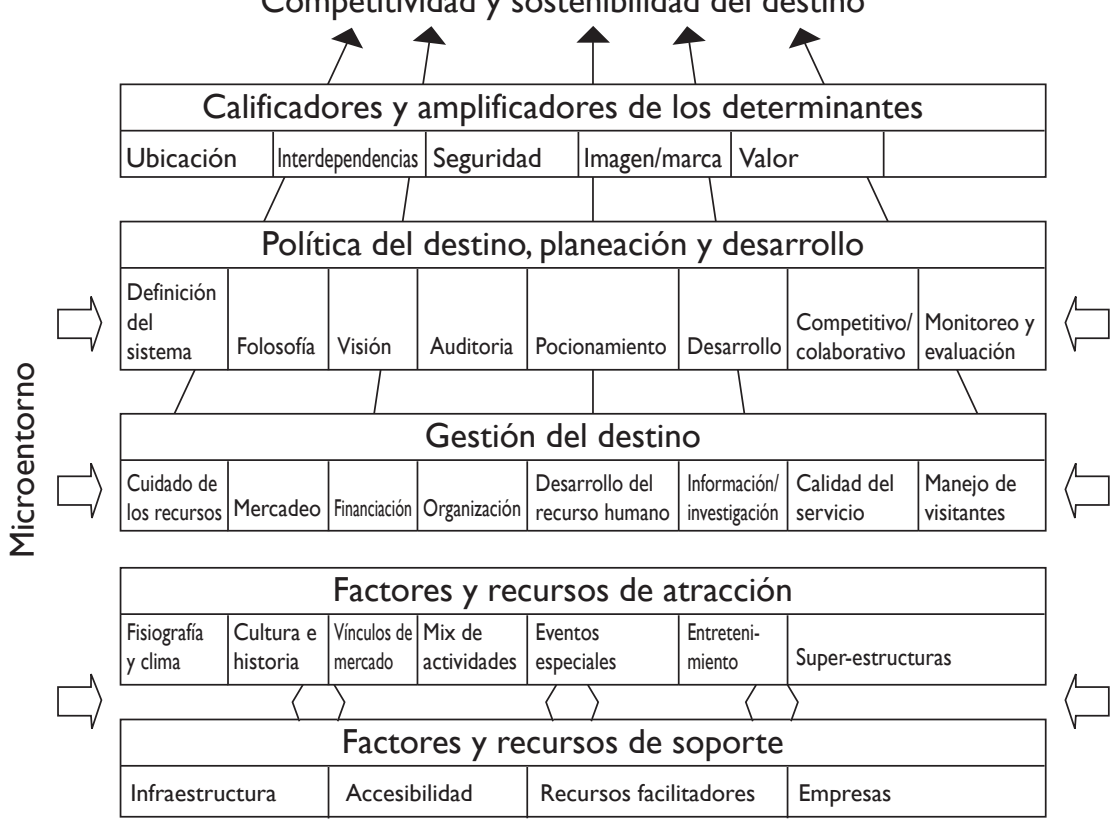

Figura 2. Modelo de competitividad de Ritchie y Crouch

El modelo de Dwyer y Kim fue aplicado a una muestra de turistas australianos que visitaron Corea del Sur y a otra de turistas coreanos que visitaron Australia, tomando a Japón, Hong Kong, Malasia, Tailandia, Taiwán, China, Singapur, Indonesia y Nueva Zelanda como referencias para establecer comparaciones entre los destinos turísticos (Francés, 2003).

Evidencia de la dificultad que entraña la cuantificación de la competitividad de los destinos turísticos y de la elección correcta de sus indicadores es que el World Travel and Tourism Council (WTTC), institución que agrupa a las 100 empresas líderes del sector del turismo y viajes en el mundo, puso en marcha, en el año 200I, un observatorio de competitividad turística, basado en ocho grandes apartados, cada uno compuesto, a su vez, por un conjunto de variables 


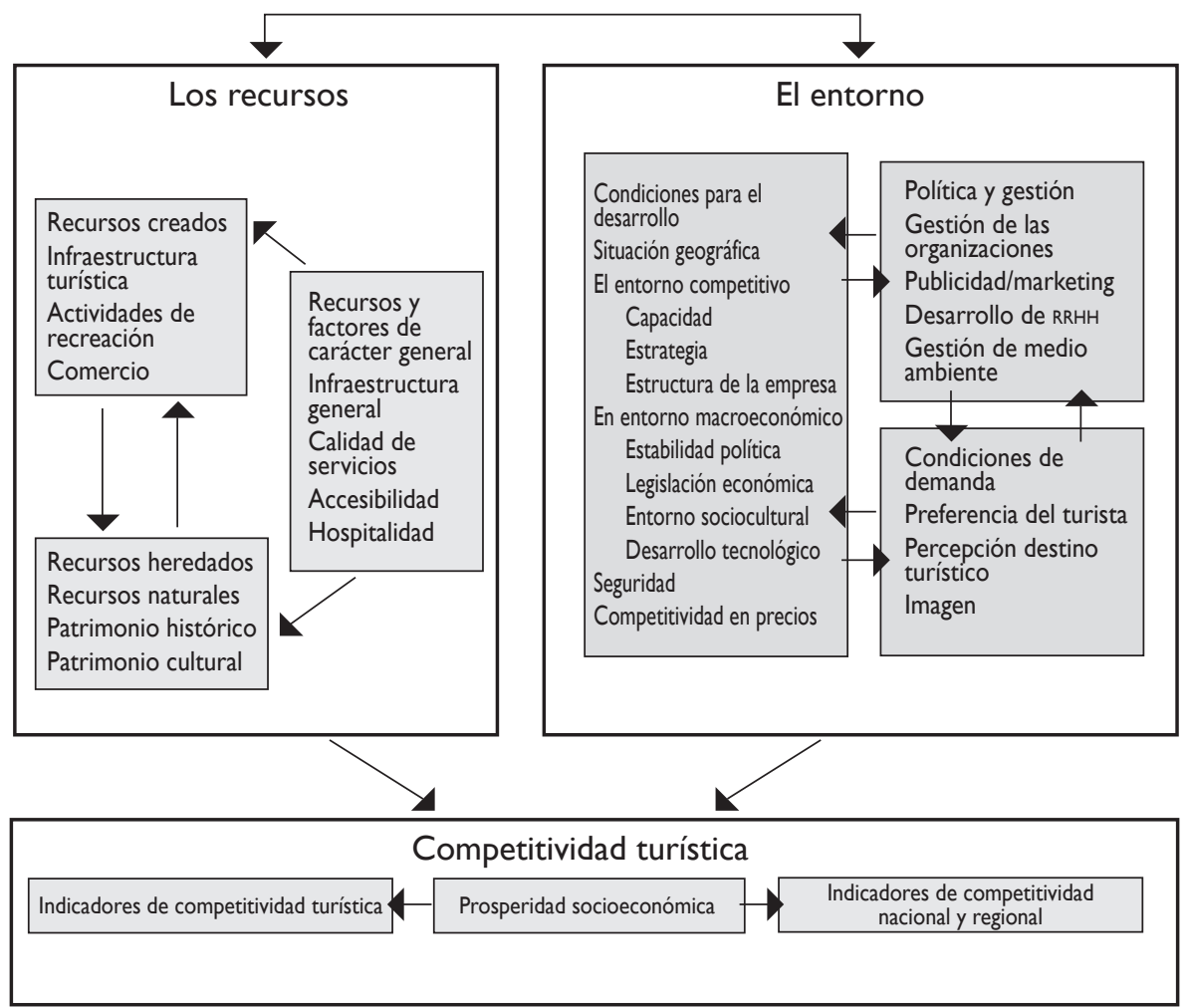

Fuente: Dwyer y Kim, 2003 citado por Bravo Cabria, 2004.

Figura 3. Modelo integrado de COMPetitividAd de UN DEstino turístico

que hacen las veces de indicadores de competitividad. Pues bien, esta batería de indicadores tiene, en general, pocos elementos en común con el conjunto de índices propuestos por Dwyer y otros (200I). A título puramente indicativo, estos ocho apartados y algunos de sus correspondientes indicadores son los siguientes:

a) Competitividad en precios: competitividad de precios turísticos, precios hoteleros, paridad del poder de compra, impuestos sobre bienes y servicios, y precios al consumo ajustados 
b) Turismo humano: índice de participación en el turismo internacional, tasa de crecimiento de llegadas de turistas internacionales, exportaciones internacionales de turismo y viajes, consumo internacional, balance turístico internacional y nueve indicadores más

c) Infraestructura: carreteras, acceso a la sanidad, ferrocarriles, índice de infraestructura y acceso al agua potable

d) Medioambiente: densidad de población, emisiones industriales de $\mathrm{CO}_{2}$ y ratificación de las medioambientales

e) Tecnología: servidores de Internet, líneas telefónicas, teléfonos móviles, exportaciones de tecnología e índice tecnológico

f) Apertura turística: necesidad de tarjeta visa, grado de apertura a los flujos turísticos internacionales, apertura al comercio internacional e impuestos sobre el comercio internacional

g) Desarrollo social: índice de desarrollo humano, periódicos diarios, ordenadores personales, acceso a la televisión e índice de criminalidad

h) Recursos humanos:esperanza de vida,tasa de analfabetismo,empleo directo en turismo y tasa de desempleo, crecimiento poblacional, empleo femenino en el sector servicios y 15 indicadores más

En el marco de los trabajos del Foro Económico Mundial, realizado en Davos, Suiza, en enero de 2007, y en reconocimiento a la importante contribución del turismo a la economía mundial, al constituirse en un motor de crecimiento y de desarrollo económico para una gran cantidad de naciones, se dio a conocer un estudio denominado Índice de Competitividad deViajes y Turismo, el cual destaca la competitividad del sector turístico en I 24 países.

El documento establece trece variables estructuradas por elementos propios del sistema turístico, así como otros elementos con injerencia directa en la realización de la actividad: reglas y regulación de la política, regulación del medio ambiente, seguridad, salud e higiene, prioridad del transporte y del turismo, infraestructura del transporte aéreo y terrestre, infraestructura turística, infraestructura de tecnologías de la información y la comunicación, competitividad de precios en la industria de los viajes y el turismo, recursos humanos, percepción nacional del turismo,y recursos naturales y culturales. Estos factores se agrupan en tres rubros de análisis temáticos: marco regulador, entorno empresarial e infraestructura, $y$ 
recursos humanos, culturales y naturales, los cuales a su vez generan puntajes que integran el índice general de la evaluación (WEF, 2007).

En vista de la amplitud y variedad de los indicadores de competitividad turística empleados en la literatura, se hace patente la enorme dificultad que conlleva la cuantificación de la competitividad de los destinos turísticos por su indiscutible carácter multidimensional y por la ausencia de consenso respecto a los indicadores que deben utilizarse.

\section{El turismo en Manzanillo}

Manzanillo es hoy la zona turística más importante del estado de Colima. Es el municipio más grande del estado, y se localiza a $98 \mathrm{~km}$ de la ciudad de Colima. Limita al sureste con el municipio de Armería, al sur con el Océano Pacífico, al noreste con el municipio de Coquimatlán, al norte con el de Minatitlán, al noreste y oeste con el estado de Jalisco. Su clima se clasifica como cálido subhúmedo y su temperatura media anual es de $26.9^{\circ} \mathrm{C}$, con periodos de lluvias en verano entre junio y octubre (INEGI, en línea).

Su población asciende a 137842 habitantes (INEGI, 2005). Sus principales ejes carreteros son: Colima-Manzanillo, Manzanillo-PuertoVallarta, ManzanilloMinatitlán, Ramal-Aeropuerto, Cuyutlán-Manzanillo y Libramiento-ColomosTapeixtles, que comunica a Manzanillo con todo el estado y el país. La transportación foránea se realiza por medio de múltiples líneas nacionales; en el interior del municipio existe transportación rural y urbana, así como taxis.

El Aeropuerto Internacional Playa de Oro es el más importante del estado, pues es el único que recibe -y del que parten-vuelos internacionales. El puerto de Manzanillo brinda servicios portuarios adecuados a los requerimientos de la exportación y la importación de bienes. Las actividades económicas que más se practican en Manzanillo son la agricultura (con el cultivo de plátano, limón, coco, maíz, frijol, ajonjolí y mango), la ganadería (de ganado bovino, porcino y caprino) y la pesca (con la captura de tiburón, guachinango, sierra, lisa, pargo, dorado, marlin y pez vela).

En la industria destacan la Peletizadora del Consorcio Minero Benito Juárez Peña Colorada, la Termoeléctrica Manuel Álvarez de la Comisión Federal de Electricidad, así como plantas procesadoras de pescado (INEGI, en línea). 


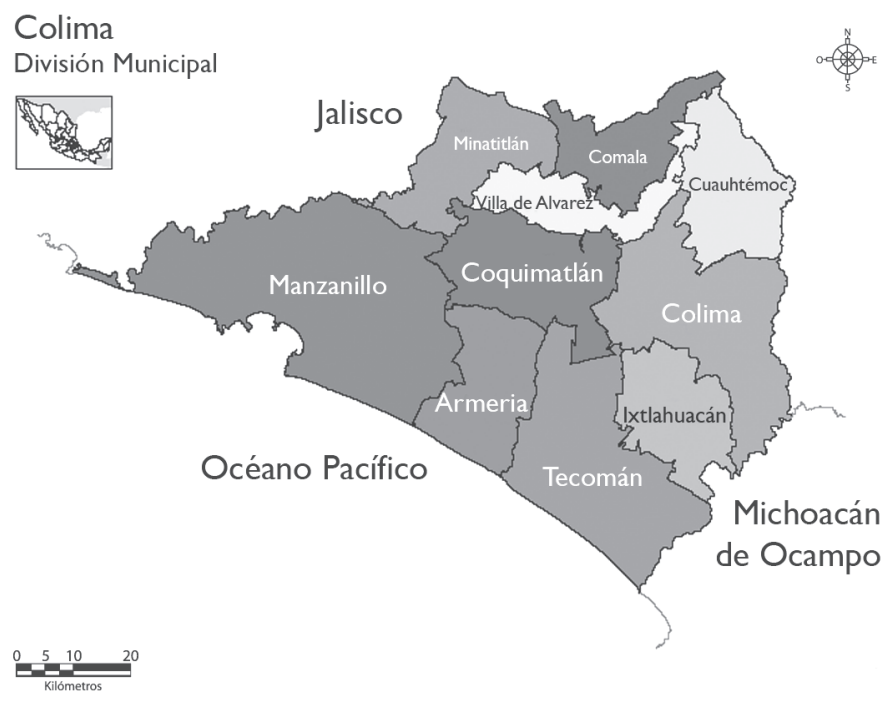

Fuente: INEGI, Marco Geoestadístico Municipal 2005, disponible en;

http://www.cuentame.inegi.gob.mx/mapas/pdf/entidades/div_municipal/colimampios.pdf.

Figura 4. Mapa de la división municipal del estado de Colima

Por sus condiciones naturales, Manzanillo cuenta con lugares propios para el desarrollo turístico, el cual constituye una actividad de vital importancia para el progreso socioeconómico del municipio.

En 2006, prestaban sus servicios en el estado de Colima 635 empresas turísticas, generando un total de 8072 empleos, y operaron en la entidad I6I establecimientos de hospedaje -la mitad de ellos en Manzanillo.

De acuerdo con la información presentada, no cabe duda de que la actividad turística juega un papel relevante para la economía estatal y, de manera muy particular, para la economía del municipio de Manzanillo (veáse gráfica I).

Sin embargo, existen datos que sugieren que este polo de desarrollo no puede ser considerado competitivo en el plano nacional ni en el regional. Un indicador básico es el porcentaje de ocupación hotelera: los textos del área señalan que el porcentaje de ocupación aceptable es de 65\% (Lundberg, 
La competitividad turística: imperativo para

Manzanillo, Colima

Sta-venga y Krishnamoorthy, 1995), frente a un promedio estatal de $49.30 \%$ y de $52.07 \%$ en Manzanillo. Esto significa que aproximadamente uno de cada dos cuartos de hotel permanece desocupado a lo largo del año (veáse cuadro I).
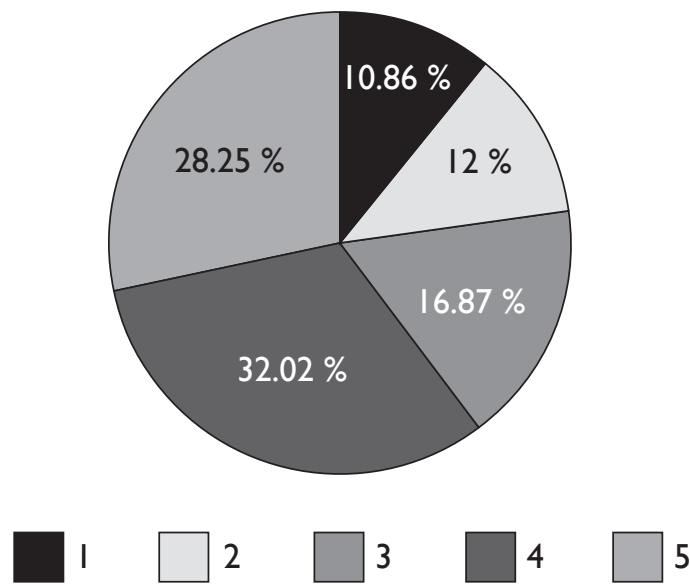

Porcentaje de cuartos por estrellas en Manzanillo

Fuente: Elaboración propia con datos del 3er. Informe de Gobierno del Estado, 2006.

Gráfica I. Porcentaje de ocupación hotelera en Manzanillo, 2006

Cuadro I.Afluencia y derrama económica en Manzanillo

\begin{tabular}{ll}
\hline \multicolumn{2}{c}{ Indicadores } \\
\hline Afluencia de turistas & 791710 turistas \\
Gasto promedio diario & $\$ 1569.16$ \\
Derrama económica & $\$ 2733095863$ \\
Estancia promedio & 2.2 días \\
Coeficiente de ocupación & $52.07 \%$ \\
\hline
\end{tabular}


Otro indicador significativo para medir la competitividad es la atracción de la inversión. El informe del gobernador Silverio Cavazos menciona que durante 2006 se invirtieron en el estado más de 47 millones de pesos. No obstante, la parte más cuantiosa de esta inversión fue pública, de los gobiernos federal y estatal; la inversión privada y/o municipal, sólo representó un porcentaje de $13.77 \%$, frente a un promedio de $86.23 \%$ en el territorio nacional (cuadro 2 ).

CUADRO 2. INVERSIÓN EN EL TURISMO DEL ESTADO, 2006

\begin{tabular}{lcc}
\hline Modalidad de la inversión & $\begin{array}{c}\text { Monto autorizado } \\
\text { (en pesos) }\end{array}$ & Porcentaje \\
\hline Estatal & 25 I35 064.3 & 53.13 \\
Federal & 15655 II4.8 & 33.09 \\
Privada y/o municipal & 6514 I54.2 & 13.77 \\
\hline Total & 47304333.3 & 100.00 \\
\hline
\end{tabular}

Fuente: Elaboración propia con datos del 3er. Informe de Gobierno del Estado, 2006.

Aún más preocupante resulta la proporción de inversión turística que atrajo el estado de Colima frente a sus principales competidores(Presidencia de la República, s.f.), destacando el hecho de que la entidad quedó muy rezagada frente a otras que representan una competencia directa: Guerrero, que atrajo 723 millones de dólares; Nayarit, I 36 millones; y Sinaloa, I08 millones.

\section{La competencia directa de Colima en el sector turismo}

El problema de competitividad turística del estado de Colima y de su polo de desarrollo más sobresaliente, Manzanillo, no tiene una fácil solución. Desafortunadamente, el destino se encuentra ubicado en una región geográfica de México caracterizada por una oferta turística muy semejante, con atractivos casi idénticos, y no cuenta con elementos que lo distingan. En la costa del Pacífico mexicano existen por lo menos siete destinos importantes con lo que en el lenguaje turístico se denomina oferta de sol y playa, sin mencionar destinos y corredores emergentes. En el mercado turístico mundial, la oferta de sol y playa 
es considerada un commodity. En los cinco continentes hay cientos de destinos con una oferta parecidísima. Para el sofisticado viajero contemporáneo esto ya no resulta suficiente, por lo cual debe acompañarse con algún otro tipo de servicio que haga peculiar al destino.

Con base en criterios de expertos, se obtuvieron los siguientes atributos que se valoran en un destino turístico (veáse cuadro 3 ).

\section{Cuadro 3.Atributos APORTAdos POR lOS EXPERTOS}

\begin{tabular}{llll}
\hline I & Amabilidad de los empleados & II & Cantidad de entretenimiento disponible \\
2 & Hospitalidad de la gente & I2 & Accesibilidad a los recursos públicos \\
3 & Precio acorde a la calidad & 13 & Seguridad personal \\
4 & Calidad del hospedaje & 14 & Sistema de telecomunicaciones \\
5 & Restaurantes & 15 & Sistema carretero del destino \\
6 & Comida local & 16 & Calidad del aeropuerto \\
7 & Clima agradable & 17 & $\begin{array}{l}\text { Apoyo gubernamental e institucional } \\
\text { al turismo }\end{array}$ \\
8 & Oferta cultural & 18 & Limpieza del destino \\
9 & Accesibilidad del destino & 19 & Calidad del agua \\
10 & Reservación del destino & & \\
\hline
\end{tabular}
Fuente: Elaboración propia.

Desde el punto de vista de la competitividad turística, es vital conocer las expectativas y percepciones que tiene los turistas, los habitantes y los empresarios turísticos del sitio en cuestión. En una investigación de campo se pudo observar la apreciación de los visitantes respecto a cada uno de los atributos, manifestando niveles de insatisfacción con la oferta cultural, la accesibilidad del destino, las reservaciones, la cantidad de entretenimiento, la accesibilidad a recursos públicos y la seguridad personal (véase gráfica 2).

El bienestar de los habitantes del destino es un indicador fundamental de la competitividad turística. Con referencia a cada uno de los atributos, los residentes piensan que debe mejorarse en cuanto a la amabilidad de los empleados, al precio -que esté acorde con la oferta turística en materia de calidad-, al hospedaje, la accesibilidad del destino, las reservaciones, la cantidad de entretenimiento disponible, la calidad del aeropuerto, la limpieza del destino y la calidad del agua (véase gráfica 3 ). 


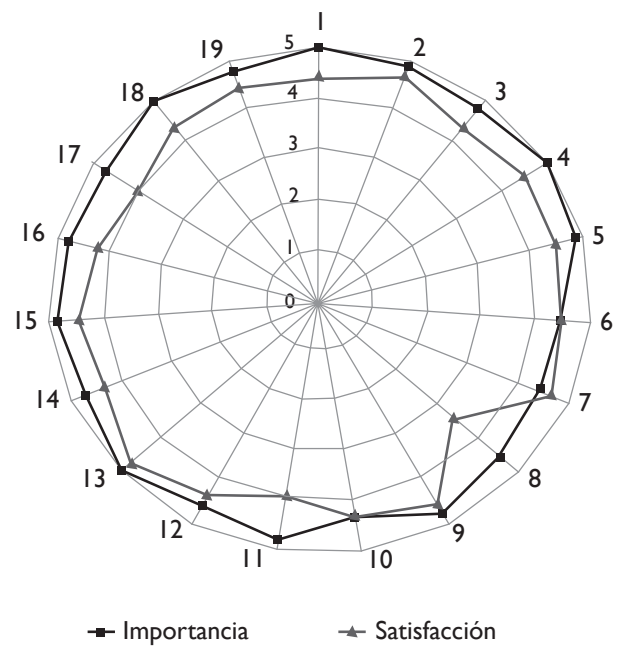

Fuente: Elaboración propia.

Gráfica 2. Nivel de SATISFACCIÓN E IMPORTANCIA dE LOS ATRIBUtOS EN LOS VISITANTES

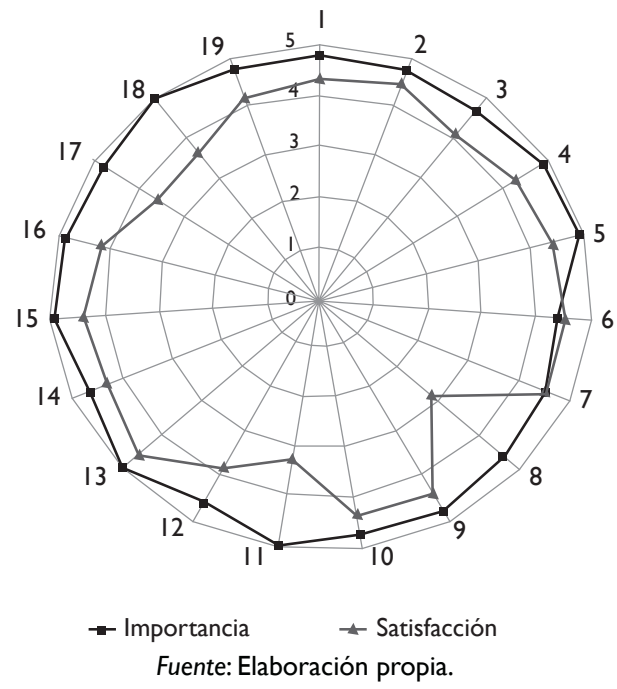

Gráfica 3. NiVEL de SATISFACCIÓN E IMPORTANCIA DE LOS ATRIBUTOS EN LOS RESIDENTES 
El empresario turístico es un actor fundamental en el destino, y opina que en Manzanillo es necesario mejorar en la amabilidad de los empleados, que el precio sea una clara manifestación de la calidad, que haya mayor diversidad y cantidad de oferta cultural, y perfeccionar los rubros de la accesibilidad del destino y su reservación, la cantidad de entretenimiento disponible, la calidad del aeropuerto, y la limpieza y calidad de la ciudad.

La estimación de estos atributos por parte de los turistas, los residentes y los empresarios coincide, $y$ evidencia que aquellos que requieren mejorar urgentemente son la oferta cultural y la cantidad de entretenimiento (gráfica 4).

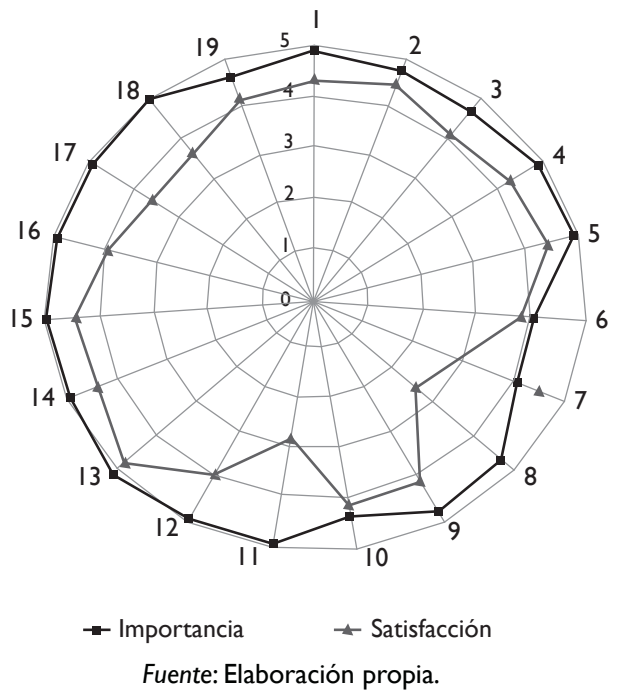

GRÁfica 4. NiVEL de SATISFACCIÓN E IMPORTANCIA DE LOS ATRIBUTOS EN LOS EMPRESARIOS

Las acciones sugeridas por turistas, empresarios y habitantes para mejorar la competitividad turística en Manzanillo son:

- Trabajar en conjunto el sector público y el privado

- Mejorar la cultura turística

- Mejorar la calidad de los establecimientos turísticos en general

- Desarrollar el turismo de forma sustentable 
- Fomentar más actividades culturales y deportivas

- Impulsar la inversión

- Perfeccionar la infraestructura turística

-Apoyar la promoción y difusión turísticas

\section{Conclusiones}

Del presente trabajo se pueden extraer algunas ideas interesantes para la investigación de la competitividad turística, que exponemos a modo de conclusión:

- Para competir en el ámbito turístico, un destino, además de ventajas comparativas, precisa de ventajas competitivas, es decir, no sólo es necesario poseer una variedad más o menos amplia de productos y recursos turísticos, sino que éstos deben ser gestionados de forma eficiente $y$ eficaz a mediano y a largo plazos.

- Los principales modelos de competitividad turística propuestos en la literatura -el de Crouch y Ritchie (1999) y el de Dwyer y Kim (2003) - coin-ciden en la multiplicidad de factores que confluyen en la competitividad de un destino turístico, por lo cual ésta se convierte en un concepto que no puede ser analizado sin considerar una perspectiva multivariante. Estos modelos son de gran utilidad cuando se trata de examinar los factores determinantes de la competitividad en los destinos, sea para realizar un diagnóstico o para formular estrategias de desarrollo.

- Manzanillo necesita con urgencia elevar su competitividad turística, perfeccionando la infraestructura, los factores de apoyo y la administración del destino, $y$ logrando un posicionamiento superior en el mercado a través de una mejor imagen real y percibida.

\section{FUENTES CONSULTADAS}

Bravo Cabria, M. S. (2004). "La competitividad del sector turístico”. Boletín Económico, Banco de España, núm. 9, 89-106.

Crouch, G.I.,J.R.B. Ritchie y S. Hudson (2000) “Developing operational measures for the components of a destination competitiveness/sustainability 
model: consumer versus a managerial perspectives", en Mazanec,J.A., Crouch, G.I., Ritchie J.R.B.y Woodside,A. G. Consumer Psychology of Tourism, Hospitality, and Leisure; CABI Publishing, I-I8,

- y J. R. B. Ritchie (1999). "Tourism, competitiveness and societal prosperity”.Journal of Business Research, 44, I37-I 52.

Dwyer, L. y C. Kim (2003). "Destination competitiveness: determinants and indicators". Current Issues in Tourism, 6 (5), 369-4I 4.

- y otros (200I). Destination competitiveness: development of a model with application to Australia and the Republic of Korea. Ministry of Culture and Tourism, Korea Tourism Research Institute (Republic of Korea), Department of Industry, Science and Resources, CRC for Sustainable Tourism, Australia-Korea Foundation (Australia).

Francés, A. (2003). Turismo: competitividad y estrategia. Caracas: Ediciones IESA. Instituto Nacional de Estadística, Geografía e Informática (INEGI), disponible en http://www.inegi.gob.mx [2006, 22 de septiembre].

INEGI (2005). II Conteo de Población y Vivienda 2005. México: Instituto Nacional de Estadística, Geografía e Informática.

Lundberg, Donald E., Mink H. Stavenga y M. Krishnamoorthy (1995). Tourism Economics. Nueva York: John Wiley.

Porter, M. E. (1998). The competitive advantage of nations. Nueva York:The Free Press.

Presidencia de la República (s.f.) "Cumplen meta de inversión turística” [en línea]. Disponible en: http://www.presidencia.gob.mx [2006: 21 de septiembre].

Ritchie, J. R. B. y G. I. Crouch (2000). "The competitiveness destination: a sustainability perspective”. Tourism Management, 2 I, I-7.

WeF (2007). The World Competitiveness Report. Lausana:World Economic Forum. 